\title{
Pedagogically mediated listening practices; the development of pedagogy through the development of trust
}

\author{
Helen Lyndon, Tony Bertram, Zeta Brown and Chris Pascal \\ Centre for Research in Early Childhood, UK
}

This paper reports on a segment of $\mathrm{PhD}$ research which was undertaken to develop participatory pedagogy working specifically within a praxeological paradigm (OliveiraFormosinho and Formosinho 2012a; Pascal and Bertram 2012). It focuses on the development of listening practices through a process of pedagogic mediation (OliveiraFormosinho and Formosinho 2012b). The research was carried over two academic years in a private day care setting in England and aimed to enhance pedagogic practice with three and four-year olds.

This qualitative methodology encompassed ethnographic techniques to develop a case study (Stake 1995). It researched the development of participatory practice through pedagogic mediation, as developed by the Childhood Association, Portugal (OliveiraFormosinho and Formosinho 2012b). This paper reports on two listening methods which were developed between researcher, practitioner and the children in the setting. These methods demonstrate the co-constructed participatory pedagogy and the isomorphic nature of learning (Formosinho and Formosinho 2016).

Keywords: praxeology, pedagogic mediation, listening to children, participatory pedagogy, professional development

\section{Introduction}

Participatory pedagogy offers an alternative to the traditional, transmissive pedagogical approach (Freire 1996) and appreciates the complex nature of early childhood. The concept of the child within participatory pedagogy is that of a competent and social being who has agency and constructs their own knowledge and understanding in collaboration with others. A participatory approach has democracy at the core and asserts the rights of both children and practitioners (Fochi and Sousa 2017).

This paper shall focus upon the development of participatory pedagogy during a larger study which was undertaken to explore better ways of listening to children. The research asked the primary question: how can listening practices be improved in early 
years settings through pedagogic mediation? Whilst the broader research took place in three early years settings over two academic years, this paper shall report on two of the participatory techniques, photo-boards and concentric circles, developed within one of those settings; a private nursery in central England with a cohort of children aged three and four years.

A focus on listening to children has been evident in the international early years research sector for some time (Clark 2018) with rights-based research, focusing on the participation of children in decision making (e.g. Lundy and McEvoy 2011), gathering increasing momentum. Whilst there is yet to be a uniform definition of children's voices or listening practices, there remains agreement that listening is multi-modal, including non-verbal cues and requires interaction and response (e.g. Bath 2013; Brooker 2011; Coleyshaw et al 2012; Williams 2009). This makes a listening approach or children's voices an integral element of participatory pedagogy.

Within the English context of this research a participatory pedagogy which seeks to listen to the voices of children sits in contrast to the increasing focus on school readiness within the sector (Brooks and Murray 2018). Whilst the English early years framework recognises the unique child and seeks to be guided by children's interests (DfE 2017) there is a prevailing discourse of readiness and a political emphasis on the implementation of the direct teaching of mathematics and literacy skills, specifically phonics, towards the end of the early years phase (Ofsted 2017).

\section{Conceptual Framework}

The conceptual framework which underpinned this research is that of pedagogic mediation which provides a bridge between research and practice and defines the researcher role throughout. Pedagogic mediation was initially developed by the Childhood Association, Portugal (Formosinho and Oliveira-Formosinho 2008; OliveiraFormosinho and Formosinho 2012b) and seeks to provide context-based teacher education which in turn develops practice. Teacher education, in this context, is more than initial teacher training and aims to transform teachers' beliefs and values (Formosinho and Oliveira-Formosinho 2008). It is part of a wider participatory pedagogy which holds democracy as central to early childhood spaces and is applied to parents, children and practitioners throughout all areas of practice (Formosinho and OliveiraFormosinho 2008). It is a strategy which remains responsive to the wider needs of the setting and to the practitioner themselves and requires time, patience and lasting 
commitment to change. Within this Portuguese approach the pedagogic mediator is seen as an 'experienced pedagogical companion' (Formosinho and Oliveira-Formosinho, $2008,40)$ who is also guided though supervision.

Highly theoretical in its nature, pedagogic mediation is influenced by the consciousness that Freire (1996) seeks to raise through a liberating and empowering approach to education; it recognises that lasting change can only come from the practitioner themselves. It has democratic values (as defined by Dewey 1916) and understanding of the possibilities of human nature.

The mediation element recognises the social nature of learning and is derived from Vygotsky's original concept of mediation (Vygotsky 1978) which proports that all interactions are mediated and so our perceptions of the world are unique to our experience and understanding; in developing understanding and challenging longstanding pedagogical assumptions, practice shifts.

Within pedagogic mediation there are four elements; openness, listening, suspending and encountering (Sousa and Formosinho 2014). The first stage, openness, allows the pedagogic mediator time in the environment and time to build relationships; this enables the mediator understanding of the pedagogy of the setting including the routine, curriculum, working practices of the staff as well as the challenges which may be faced. Stage two, listening, begins to enable reflection; the mediator has a supportive role here and models what this reflective process may look like. Suspending, stage three, gives the practitioners the opportunity to begin to develop thinking around and answer some of their own problems; this section can take time and practitioners are not pressured to move forward or make changes to practice that they are not yet ready to make. The pedagogic mediator needs to respect the practitioner's right to develop at their own rate and this is where the suspension takes place. Finally stage four, encountering, is the transformative space where practice is questioned. This is stage is responsive to the needs of the practitioner and enables them to develop their own pedagogical understanding.

There is a proposed isomorphism in operation throughout this process (Formosinho and Formosinho 2017). Democracy is a core value and permeates the early childhood setting. As the pedagogic mediator treats the practitioner in one way, so the practitioner then treats children similarly, resulting in a democratic, valued and developmental experience. A co-constructed participatory pedagogy is by its very nature isomorphic (Formosinho and Formosinho 2016). 
The use of pedagogic mediation in this research is also situated and context based. Differences on a systemic level in early childhood education and care mean that settings within the English framework, operating within the Early Years Foundation Stage Framework (DfE 2017), do not require practitioners to have qualified teacher status and have different specific requirements regarding continued professional development. Pedagogic mediation was utilised as a research lens and guided the practice and conduct of the researcher. The style of pedagogic mediation needed for this research to progress could not remove practitioners from time with children, which would represent a cost to settings, and needed to fit with the routines and availability of the settings.

The communal nature of pedagogic mediation in this research could be likened to communities of practice (Wenger 1999) through which the groups and networks which support the work of the individual are recognised. The various layers of participation offered by communities of practice are similar to the differences in relationships that would exist with the pedagogic mediator within the setting; not all practitioners are ready to change at the same pace, practitioners may choose to engage in legitimate peripheral participation for some time before engaging fully in the process (Wenger 1999).

\section{A participatory paradigm}

This research took place within a praxeological paradigm which provides an understanding of 'phronesis, praxis, ethics and power,' (Pascal and Bertram 2012, 477) and so its links to Freire (1996) are implicit. Emphasising the importance of practice-led enquiry, praxeology holds ethics centrally; it balances power providing participatory approach to research whilst recognising the multiplicity of perceived realities and participatory experiences.

Researching within a praxeological paradigm brings ethical considerations to the fore and this reflects the researchers deeply rooted axiological beliefs around participation and rights. A specific goal of the research was to flatten the naturally occurring hierarchical structures through the process of mediation and to ensure democratic principles were applied throughout the research. Most notably the equitable approach offered through praxeology aims to redistribute power in a democratic, inclusive and collaborate way (Pascal and Bertram 2012, 486). 


\section{Methods}

The research was undertaken in a semi-rural location in central England. A geographical cluster of settings had begun to work collaboratively within a potentially competitive economic environment; all settings essentially competing with one another to attract families to register. The cluster collaboration was the result of a perceived reduction in support from local authority sources due to budget restrictions which were impacting on services across England at this time with 'significant decreases in funding being experienced by local authorities, and the huge competing pressures, .... a strain on early years services' (Bertram and Pascal 2014, 13). The settings and the local infant school, to which their children all transitioned, began to develop a range of collaborative strategies in order to support pedagogical developments. The setting specific to this paper is a private setting which provides funded care for two, three and four-year olds. At the time of the research the setting had 36 children registered; with the specific cohort involved in the research there were four part-time practitioners, qualified to level 3 (nongraduates), working with a cohort of sixteen children aged three and four years.

The research design utilised ethnographic techniques whilst recognising their potential for empowerment and change (Robinson 1994). The data collection period lasted two academic years during which time a case study (Stake 1995) was built around the setting. The case study was determined by collaboration between researcher, practitioners and children. In this case the practitioner responsible for the education and care of the preschool aged children (three and four years of age) worked alongside the researcher to develop participatory pedagogy and specifically focused upon how the voice of the child within the group was captured and then informed practice.

The setting was visited on a weekly basis over the duration of the research period and following each visit researcher reflections were recorded. An extended research period enabled the researcher to develop meaningful relationships with those in the setting. Notes were recorded on the same day as the visit to retain integrity of information gathered:

'...the discussion turned to the wider environment and the staff opened up about their frustrations with the layout of the building; they feel that it 
restricts the possibilities. I asked questions about how the children use the current space and that prompted lots of discussion. By the end of the session the staff were talking about opening the setting up at the weekend to enable them to have dedicated time and space to reconsider the layout and priorities. They are going to use their observations of the children to guide their decisions and they asked me to be a part of that process...'

\section{Ethics}

Consent was gained across all settings which outlined anonymity, confidentiality of data and participants rights to withdraw. An agreement was reached with all setting managers to provide broad pedagogical support as guided by the practitioners. This pedagogical support was to be in keeping with a participatory approach and within the remit of pedagogic mediation. Ethical guidance cites non-malevolence and sets a standard that researchers should not do harm or cause stress to participants (EECERA 2015); praxeology takes this further offering guiding principles for the praxeological researcher which ensure it is 'essentially and radically egalitarian' and a commitment through participation to transformation (Pascal and Bertram 2012,486). Relationships were, therefore, a key ethical consideration, as without trusting and mutually respectful relationships the research would be compromised. The first stage of pedagogic mediation, openness, allows time for such relationships to develop. Given the researchers postgraduate qualifications and professional heritage there was the potential for power imbalance; thorough exploration of concepts of power ensured awareness of the potential to be defined as an 'expert' (Freire 1996). Through developing honest and open relationships with practitioners, power was mitigated, and a collegiate working relationship developed. The EECERA ethical guidelines were adhered to throughout (EECERA 2015) and ethical approval was provided by the supervising University. 


\section{Data collection and analysis}

Researcher reflections were then thematically coded (Boyatzis 1998) assigning interactions to the different stages of pedagogic mediation; openness, listening, suspending and encountering. The mediated encounters were also coded for the quality and depth of information that they provided. This numerical coding, on a scale of one to three, was based on Geertz' concept of thick description (1973) and interactions which provided lots of detail and description, coded as three, went forward for analysis. Finally interactions which fulfilled the research theme of 'listening to children' were also coded accordingly.

Of those 'listening to children' interactions, some were specifically planned activities in which children's views were sought and these activities were also then subject to a secondary stage of analysis in order to actively 'listen' to the children. Photoboards and concentric circles were produced by the children and then analysed collectively. Interpretation was co-constructed by practitioners, children and researcher. This enabled clarification and verification of the children's original intent. This discussion enabled further analysis facilitated by the researcher. This included: coding activity-based images such as construction play, role play and art-based activity; coding for indoor or outdoor preference and sub-categories within this; social coding for adult and child relationships.

\section{Findings}

Through coding against the stages of pedagogic mediation and through application of a scale of thick description (Geertz 1973), significant pedagogic interactions were identified. In the case of the nursery setting described over fifty such interactions were recorded over the period of two years. These interactions were deep pedagogical discussions that all could be linked to better listening strategies.

The listening methods which developed as part of these pedagogic discussions were co-constructed with children, practitioners and setting leadership, to adhere to 
policies and legislation. Their inception was borne largely from the encountering phase of mediation as practitioners and researcher discussed how best to develop listening practices and incorporate the views of the children. This can be illustrated through this researcher reflection that evidences how the practitioner became the catalyst for the development of listening methods and how they included the children:

'Today I felt challenged; the practitioner wanted to know what other suggestions [for listening strategies] I had to bring. She has asked me to go back to the academic research and see what other inspiration I can find before my visit next week; she would like to be able to evaluate their upcoming educational visit and has said that logistically the camera will not facilitate this in the way they are currently working [one shared between a group]. She will discuss with the children their ideas for evaluation as she knew it needed to be meaningful for them. Today I could feel a shift in the momentum of the research; the 'encountering' was clear as we discussed possible solutions.'

\section{Participatory method 1 - Photo elicitation and photo-boards}

Inspired by the mosaic approach (Clark and Moss 2011) and previous research (Lyndon 2019), and through discussion with practitioners and children, a digital camera was introduced to the setting. The camera was the responsibility of the children and there was a collective decision, through a researcher led circle-time, that the camera would document what the children most enjoyed about their experiences. The camera was located for easy access and the practitioners facilitated its use by re-charging batteries each evening. There was an understanding that all of the photographs would act as the prompt for further discussion. It is the discussion that the photograph can elicit which supports children in forming their narratives as children demonstrate greater communicational competence when they are in control of the narrative (Formosinho and Araujo 2006); the use of the camera meant that children were in control of the image and therefor the prompt for discussion.

Photo elicitation proved popular amongst the children; in the first pilot week over one thousand images were taken by the group of sixteen children. The following week saw a reduction in the number of images being taken and an increase in the level of discernment applied; the children began using the camera for specific purposes and were aware that they could capture progress (e.g. the development of a piece of art) as well as ephemeral creations. 
The children began to define a set of rules to accompany the camera which demonstrates their participation in the development of the research method. The following illustrates an interaction between one of the children and the researcher which resulted in the children reviewing the images on a laptop before they were printed out.

Researcher: Are you making use of the camera when I am not here?

Child 'We have to share and make sure everyone takes turns... we get (child's name) to take the photos lots too, he likes it and he is good at remembering....then you get pictures of yourself. I like pictures of me. When can we see them?'

Researcher: I was going to take the camera away and print the photographs for you...

Child: but we can look at them on a computer too, that's what my dad does.

Researcher: Would that be better, to have a look on a computer? I can bring a laptop along and you can see the photographs you have taken.

Child: yes, then we say which ones were mistakes too... you don't have to print out the mistakes.

Once the children were presented with the images, they utilised these images in creating photo-boards. The construction of these simple boards was participatory as the children decided how their board was created, if at all, and which photographs were used. This produced a collage for each child which depicted their experience; alongside this was a narrative which documented the corresponding discussion and enabled more detailed consideration of the children's preferences.

The following demonstrates the narrative of Jessica's photo-board (52 months). It was written immediately following the creation of the board and explored both the functional elements of the activity as well as the researcher reflections.

Jessica spent almost fifteen minutes sorting through the photographs looking for those which she had taken or that she knew to be hers. It has been seven days since the last pictures had been taken. She selected twelve images to include in her photo-board. She then began by sticking an image of herself centrally explaining 'that way you'll know it's mine' to the researcher. She 
proceeded to add two images she had taken of the dolls in different positions. As she glued, she explained that playing with the dolls was 'the best thing to do at nursery.' There was a further image of the small world toys, Jessica explained 'these are like playing with dolls.' She added a picture of her feet wearing summer sandals 'I took this; these are my feet.' The researcher asked how she knew which photographs were hers and was informed 'they are mine, I remember, and some I asked my friends to take so I could be on them, it's all the things I like.'

She then added two pictures which showed her painting and one picture of the final painting and asked the researcher to write down 'This is my painting. I am taking it home.'

The remaining photographs were of children in the setting; once they were stuck down the researcher was instructed to write each child's name by the picture and label them all friends.

Jessica concluded the activity 'it's done, this is what I like best.'

Postscript - As she was collected from the setting Jessica wanted to show her parent the board; their conversation focused on the images of her friends and how lucky she was to have such lovely friends at nursery.

Analysis across the photo-boards demonstrated the importance of relationships which concurs with previous research (Clark and Moss 2011). The practitioners were surprised to note that the photo-boards appeared to evidence gendered play; the discussion with the children confirmed that certain activities within the nursery were the realm of either girls or boys.

\section{Strengths and limitations of photo-boards}

The children enjoyed the camera and were proficient at documenting their lived experience at nursery. They were able to recall the pictures they had taken after a period of time (in excess of ten days for some children) and were keen to participate in discussion based on these photographs. All children chose to participate in both the photography and the creation of the photo-boards. The practitioners reflected that they learned from the children through this experience.

The quantity of images collected for a small cohort of children was extensive and once 
the images were printed it was not possible to support all children simultaneously in accessing those images. There was also a significant difference in the quantity of images taken by different children as some children attended on a part-time basis whilst others were full-time. Many of the printed images were never 'claimed' and so there was no exploration of the images that were not included on the photo-boards.

\section{Participatory method 2 - Concentric circles}

The second method, which was successfully developed and implemented within an encountering phase of mediation, was a graduated approach to eliciting feedback from children. Having explored a variety of drawn methods (e.g. Anning and Ring 2004) the researcher had explored Elden's (2013) concentric circles of closeness as a graduated way of exploring children's relationships. Following requests from the children to engage in further activity along with their preference for the drawing easel, and after discussion with practitioners, the concept of concentric circles was applied to the evaluation of a visit to the zoo.

The children were given three concentric circles drawn onto large rolls of paper; this offered four spaces for their responses with the centre smallest circle being for their best experience. Figure one demonstrates the responses of Lily (38 months) who worked for approximately 20 minutes with the researcher on her response. Once she had completed her response she shared her experiences of this with the other children and explained what was required of them within the task. 


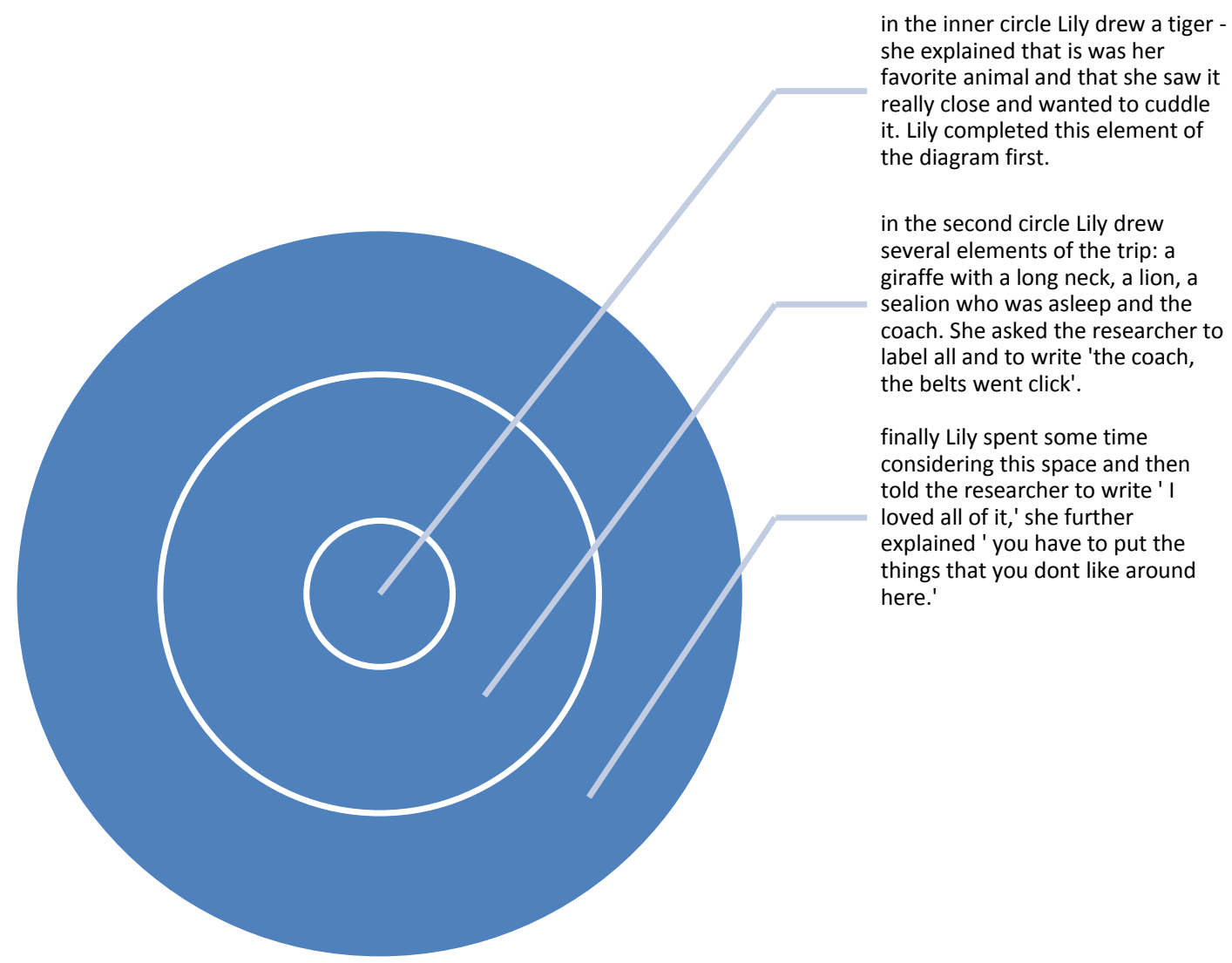

Figure 1

A co-constructed analysis of the concentric circles provided the practitioners and setting leadership with an overall evaluation of the day out. Many of the children had found the amount of walking problematic and this element features on the outer circle of three of the diagrams. Functional elements such as the coach journey and the picnic lunch had been enjoyed by the children; discussion determined that this was largely as a social opportunity and a collective experience; the children had enjoyed sitting by friends on the coach and eating lunch with friends at the picnic.

\section{Strengths and limitations of concentric circles}

The concentric circles proved to be a popular activity for the children and all who were invited to evaluate the zoo trip in this way participated. The children were keen to take the opportunity to discuss their experiences with the researcher and practitioners. Children's participation in this activity was influenced by their self-esteem and a conception that they were unable to draw; this is evident in half of all responses where 
the children commented that they could not draw a particular element, in some cases practitioners were asked to contribute and draw certain elements on the child's behalf.

\section{Discussion}

Both the photo-boards and concentric circles as research methods were developed during an encountering phase of mediation and both demonstrated participatory elements. The practitioners contributed with superior knowledge of the children and the setting and the implementation of both methods was co-constructed with the children. The practitioners decided how both activities would be embedded into the pedagogic routine and they specified how the evaluation of the activity would take place. The children in this setting demonstrated independence and took ownership of these activities; their participation was invited rather than required yet all were keen to participate. The children adapted potential parameters as necessary e.g. some children glued several pages of photo-boards together to make it as large as they wanted it to be. Some drew additional images where a photograph was not available. The children took ownership of what the adults wrote on the boards and some children elected to have no annotations on their board at all. It was at the children's behest that the photo-boards were displayed within the setting and revisited for further discussion.

The concentric circles were also adapted by the children in multiple ways. One of the children added additional circles to provide further distinctions between their preferences, several children made use of the outside space and recognised that their least favourite elements would be placed here. The children were proud of their work and elected to write their names across the front, rather than on the back, as they had been requested to do so.

Pedagogic mediation provided an effective and participatory mechanism through which listening practices could be extended and further embedded into practice. This concurs with previous research utilising a mediated and participatory approach (Fochi and Sousa 2017; Formosinho 2016; Formosinho and Sousa 2019). The practitioners reported the benefit of working alongside a pedagogic mediator; 'you're one of us now, you know what its like and you help us to think about what we do,' and 'you've really made me think about how I listen to the children. There is time in every day to make sure you notice every child and now I think about why we do things. Is it really what the children want?' 
This research affirms the notion that pedagogic mediation, as a mechanism for continued professional development, provides an effective and personalised approach; this however takes time and is based on the individual relationships that the mediator forges with practitioners and settings. In this personalised relationship, trust builds over time and the practitioner can engage in deeply challenging pedagogic discussions without fear of judgement and reprisals. In this safe space previously held pedagogic assumptions can be challenged.

\section{References}

Anning, A. and K. Ring. 2004. Making sense of children's drawings. Maidenhead: Open University Press.

Bath, C. 2013. Conceptualising Listening to Young Children as an Ethic of Care in Early Childhood Education and Care. Children \& Society 27: 361-371.

Bertram, T. and C. Pascal. 2014. Early Years Literature review. Birmingham: CREC/ Early Education. Accessed 14 ${ }^{\text {th }}$ June $2017 . \quad \underline{\text { https://www.early- }}$ education.org.uk/sites/default/files/CREC\%20Early\%20Years\%20Lit\%20Review\%202 014\%20for\%20EE.pdf

Brooker, L. 2011 Taking children seriously: An alternative agenda for research. Journal of Early Childhood Research. 9: 137-149.

Brooks, E. and J. Murray. 2018 Ready, steady, learn: school readiness and children's voices in English early childhood settings. Education 3-13. 46(2): 143 - 156.

Boyatzis, R. 1998 Transforming qualitative data: thematic code development. London: Sage.

Clark, A. 2018 'Picking up the pieces: where to next in terms of listening to young children?' Presented at EECERA annual conference Budapest: Ped Talk Group 3. $31^{\text {st }}$ August 2018.

Clark, A. and P. Moss. 2011. Listening to young children: the mosaic approach. London: NCB. 
Coleyshaw, L., J. Whitmarsh, M. Jopling, and M. Hadfield. 2012. Listening to Children's Perspectives: Improving the quality of provision in early years settings. Part of the longitudinal study of early years professional status. Dfe RR239b. London: DfE/ University of Wolverhampton.

Dewey, J. 1916. Democracy and Education. New York: Macmillan reprinted 2004 New York: Dover.

DfE. 2017. The statutory framework for the early years foundation stage. London: DfE. Accessed $14^{\text {th }} \quad$ June 2018. https://assets.publishing.service.gov.uk/government/uploads/system/uploads/attachment _data/file/596629/EYFS_STATUTORY_FRAMEWORK_2017.pdf

EECERA. 2015. Ethical Code for Early Childhood Researchers. Accessed $14^{\text {th }}$ June 2018 available at http://www.becera.org.uk/docs/EECERA_Ethical_Code.pdf

Elden, S. 2013. Inviting the messy: drawing methods and 'children's voices' Childhood 20 (1): 66-81.

Fochi, P. and J. Sousa. 2017 Participatory Pedagogies with children: making real children's rights. Presented at EECERA annual conference Bologna: Keynote. $1^{\text {st }}$ September 2017.

Formosinho, J. 2016. Pedagogic documentation: uncovering solidary learning. In Formosinho, J. and C. Pascal. (eds) Assessment and Evaluation for Transformation in Early Childhood. London: Routledge: 107 -128.

Formosinho, J. and B. Araujo. 2006. Listening to children as a way to reconstruct knowledge about children: some methodological implications. European Early Childhood Research Journal. 14 (1):21-31.

Formosinho, J. and J. Oliveira-Formosinho. 2008. Pedagogy-in-Participation: Childhood Association's approach. Research Report. Lisbon: Aga Khan Foundation.

Formosinho, J. and J. Formosinho. 2016. The search for a holistic approach in Formosinho, J. and C. Pascal. (eds) Assessment and Evaluation for Transformation in Early Childhood. London: Routledge: 93 - 106. 
Freire, P. 1996. Pedagogy of the Oppressed. London: Penguin.

Geertz, C. 1973. The Interpretations of cultures. New York: Basic books.

Lundy, L. and L. McEvoy. 2011. Children's rights and research processes: assisting children to (in)formed views. Childhood: 19(1): 129-144.

Lyndon, H. 2019 Mosaic; participatory research in early years. In Lambert, M. Practical Research Methods in Education: an early researcher's guide. London: Routledge:

Ofsted. 2017. Bold Beginnings: the reception curriculum in a sample of good and outstanding primary schools. Manchester: Ofsted. Accessed 19 September 2018 https://assets.publishing.service.gov.uk/government/uploads/system/uploads/attachment _data/file/663560/28933_Ofsted__Early_Years_Curriculum_Report___Accessible.pdf

Oliveira-Formosinho, J. and J. Sousa. 2019. Developing pedagogic documentation: children and educators learning the narrative mode. In Formosinho, J. and J. Peeters. (eds) Understanding Pedagogic Documentation in Early Childhood Education London: Routledge.

Oliveira-Formosinho, J. and J. Formosinho. 2012a. Praxeological research in early childhood: a contribution to a social science of the social. European Early Childhood Research Journal. 20 (4): 471-476.

Oliveira-Formosinho, J. and J. Formosinho. 2012b Pedagogy-in Participation: Childhood association educational perspective. Porto: Childhood association and Porto Editoria.

Pascal, C. and T. Bertram. 2012. Praxis, Ethics and Power: developing praxeology as a participatory paradigm for early childhood research. European Early Childhood Education Research Journal. 20 (4): 477-492.

Robinson, H. A. 1994. Ethnography of Empowerment. Abingdon: Taylor \& Francis.

Sousa, J. and J. Formosinho. 2014. The pedagogical mediator: A case study on pedagogical transformation. Presented at EECERA annual conference Crete: A/4. $10^{\text {th }}$ September 2014. 
Stake, R. 1995. The Art of Case Study Research. London: Sage.

Vygotsky, L. 1978. Mind in Society. Cambridge, MA: Harvard University Press.

Wenger, E. 1999. Communities of practice: Learning, Meaning and Identity. Cambridge: Cambridge University Press.

Williams, L. 2009 Listening as a way of Life: Developing a listening culture. London: NCB. 